\title{
A SIMPLE DOG HEAD HOLDER FOR USE WITH THE LAB TRONICS STEREOTAXIC INSTRUMENT ${ }^{1}$
}

\author{
Edward F. Domno, M.D. \\ Department of Pharmacology, University of Michigan, \\ Ann Arbor, Mich.
}

(Received for publication: November 27, 1959)

The use of the $\operatorname{dog}$ as an experimental animal in neuro- and psychopharmacological studies is increasing because many drugs affect the dog in a manner similar to that of man. At least two stereotaxic atlases of the mongrel and/or beagle dog already have been published (Leontovich and Mering 1956; Lim et al. 1959) and several others are in the planning stage. Hume and Ganong (1956) have described a special stereotaxic instrument for use with $X$-ray visualization of the third ventricle of mongrel dogs by means of an intraventricular injection of a radiopaque material.

Inasmuch as many investigators now possess a Lab Tronics stereotaxic instrument designed for the into the horizontal bars below the old numbers (for the cat and monkey) which were colored black. An extension of the horizontal bars and a supporting frame for the hind quarters of the animal is of value since most dogs of approximately $10 \mathrm{~kg}$. weight extend considerably beyond the horizontal bars supplied by the manufacturer.

At present, the Horsley-Clarke stereotaxic coordinates for various structures in the dog brain are estimated from serial sections of the brains of a number of pure-bred beagle dogs approximately 8 to $12 \mathrm{~kg}$. Considerable variation (up to $5 \mathrm{~mm}$.) in the coordinates between long-legged and short-legged beagles have been observed. As a result, beagle-like

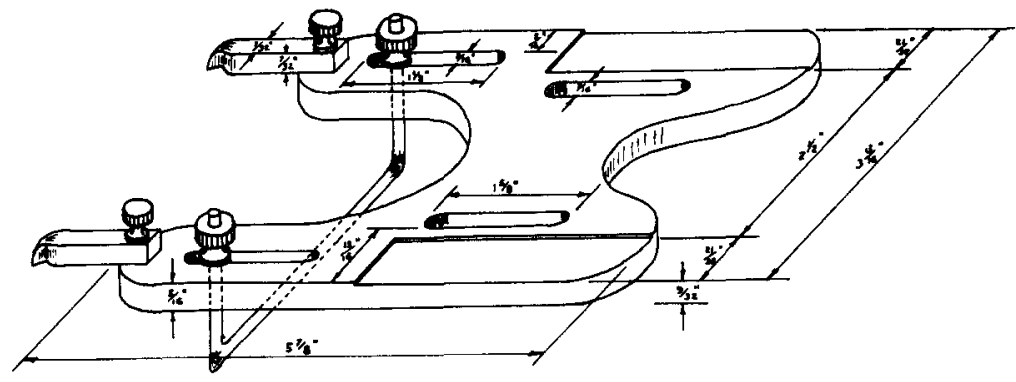

Fig. 1

Schematic diagram of the plate used for holding the dog's head in a Lab Tronics stereotaxic Instrument.

The dimensions are expressed in Inches. Those not shown are not critical. The plate can be made of stainless steel or aluminum.

cat and monkey, a holder which would fix the dog's head in the same instrument would be a distinct advantage. Lim et al. (1959) have described the type used by them. The method used in this laboratory for the past two years has been especially convenient. It simply involved a different plate for the Lab Tronics stereotaxic instrument to maintian the $d o g$ 's head in the Horsley-Clarke planes (see fig. 1 and 2). The two ear bars were shifted posterior $40 \mathrm{~mm}$. and the A-P zero for dogs established at this point. The new A-P numbering system (colored red) was stamped

1 Supported in part by grant MY 2653, U. S. Publlc Health Service. mongrel hounds have been found as satisfactory as pure breds for localizing various structures in the dog's brain.

\section{SUMMARY}

A simple dog head holder for use with the Lab Tronics stereotaxic instrument has been described.

The author wishes to acknowledge Dr. M. H. Seevers for his persistent efforts in encouraging the development of the dog as an experimental animal in studying centrally acting drugs, and Dr. S. Ueki for his assistance in designing the head holder. 


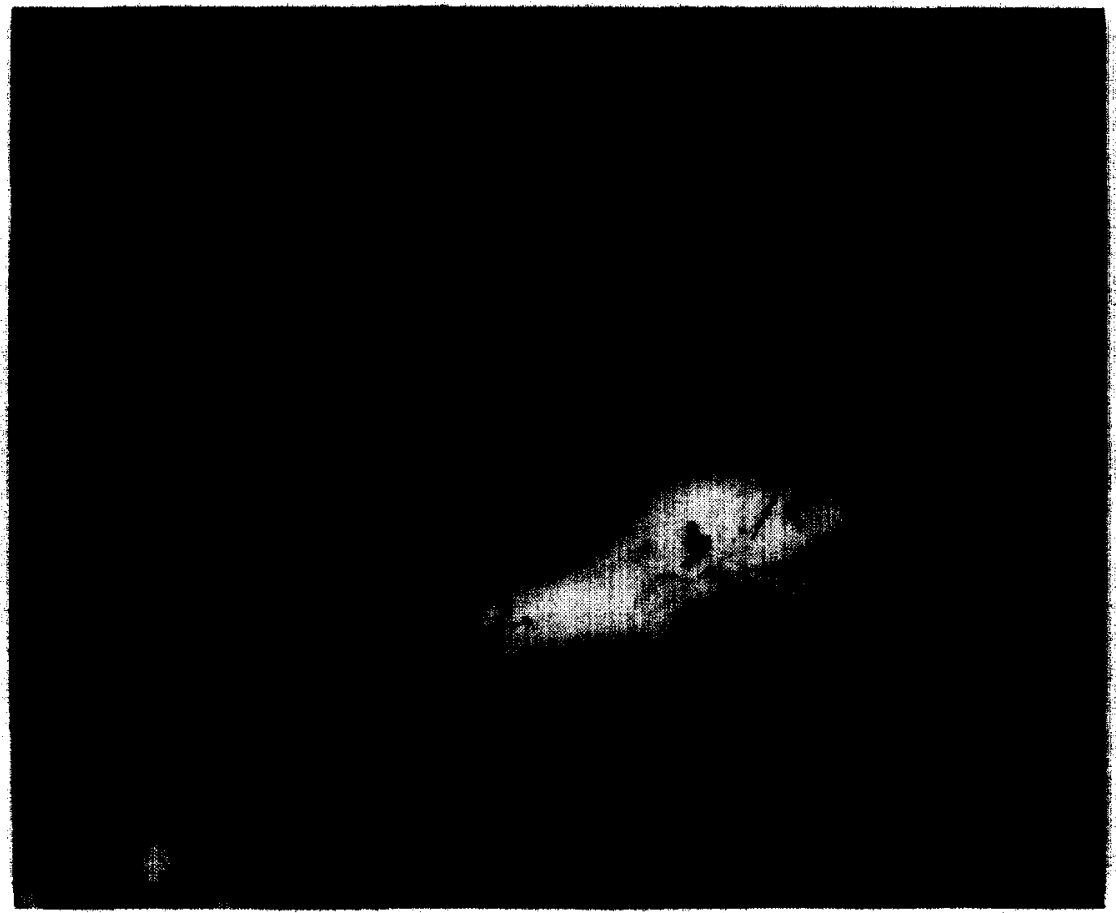

Fig. 2

Photograph of complete instrument with a dog's skull held in the Frankort plan sio that Horsley-Clarke coordinates can be used.

\section{REFERENCES}

Huxe, D. M. and GANoNG, W. F. A method for aecurate placement of electrodes in the hypothalamus of the dog. EEG Clin. Neurophysiol., 1956, $8: 136-140$.

Leontovich, T. A. and Mering, T. A. Data on the typography of subeortical formations in the dog brain in relation to experimental interferences in them. Original in Russian: Biall. Eksper. Noi. Biol. I Med., 1956, 42: 71-78. English translation in: Bull. Exper. Biol. Med., USSR, 1956, 61: 713 722.

I.im, R. K. S., LiU, Chen-Nao and Mofrith, R. L. A Stereotactic Atlas of the Dog's Brain. 1959 . ( $\therefore$ C. Thomas.

Reference: Dowino, E. F. A simple dog head holder for use with the Lab Tronics stereotaxic instrument. EEG Clin. Neurophysiol., 1900, 12: 521-522. 